\title{
The safe surgeon
}

\section{A. Sampath Kumar • Carlos A. Mestres}

Published online: 27 April 2011

(C) Indian Association of Cardiovascular-Thoracic Surgeons 2011

Cardiac Surgery has come a long way since Bailey's Mitral Valvotomy [1]. It is now very clear that heart surgery is safe effective and in some areas preserves life in terms of quality [2], although we are not sure any Cardiac Surgery can prolong life. The word prolong was perhaps used in comparison to the natural history of the disease rather than to adding extra years to one's life.

Who is a Safe Surgeon (SS)? And what does SS do differently? The current generation of busy surgeons do not have the time or inclination to adhere strictly to surgical safety recommendations. Although "safe surgeon" cannot be clearly defined, we have put down certain basic characteristics that are desirable, and hope these will help professionals to change their mindset for improved outcomes.

A SS evaluates his patient personally. It is necessary to make eye contact, discuss, and reassure the patient directly. It is very essential that SS examine the patient thoroughly and seek relevant history. SS learns to view, interpret and understand investigational reports. SS does not go by the reports only to make a surgical judgment. The surgeon does not operate on echocardiograms or angiograms, most importantly SS operates on patients.

The safe surgeon mentally prepares self and the patient for the procedure. SS must make a mental picture

A. S. Kumar $(\triangle)$

IJTCVS, A-4 (Basement), Yojana Vihar,

Delhi-110092, India

e-mail: ijtcvs2000@hotmail.com

\section{A. Mestres}

Department of Cardiovascular Surgery, Hospital Clínico,

University of Barcelona,

Villarroel 170,

08036 Barcelona, Spain of how to approach this problem at surgery, should discuss with team of assistants, anesthetists and perfusionists before surgery is begun. SS must also seek and ensure any special requirements for the patient's procedure (instruments, equipment, technique etc.).

The safe surgeon is present in the operating room. The current World Health Organization (WHO) surgical safety checklist mandates that the patient and surgeon identify each other before going under the anesthetic $[3,4]$. Remote control surgeons can easily overlook important safety precautions in addition to increasing their own anxiety. Serious complications can be effectively handled if SS is present. SS shall not betray the patient's trust.

The safe surgeon scrubs and assists the student. Nowhere is this more important than in cardiac surgery. A misplaced suture, an improper incision can lead to serious consequences. The assistants should never be neglected as they are a critical part of the surgical team, instrumental in a successful outcome [5]. The safe surgeon pays meticulous attention to technical details of the procedure. SS is ever observant and ensures satisfactory conduct of the procedure without missing steps.

The safe surgeon conserves blood, respects the tissues, restores the anatomical barriers, leaves the least amount of foreign material and reconstructs tissue planes. It is especially important to ensure a safe second operation for the patient if required, by realizing that all cardiac surgical procedures are palliative with probable exception of, ligation of patient ductus arteriosus and direct surgical closure of atrial septal defect. That redo surgery may be required and to take necessary steps to ensure safe reentry.

A safe surgeon leaves the operating room with the patient, or is present in the hospital until completion of procedure and patient settled in Intensive Care Unit (ICU). The surgeon completes the final steps of the surgical safety 
checklist without fail. A safe surgeon records his observations, ensures specimen obtained is properly processed, and leaves appropriate instructions for post surgical care.

A safe surgeon is available for any emergency arising in the patient. In the event SS is unable to be present he will inform the patient, assign another competent surgeon before leaving. A paradigmatic example of a serious and emergent situation is that of early postoperative paraplegia after repair of a thoracoabdominal aneurysm. A safe surgeon communicates openly, truthfully and directly with the patient/relatives as long as the patient needs.

A safe surgeon reviews own performance, outcomes. SS audits own performance. This is very essential for continuously improving one's results and outcomes. This is the rationale behind risk stratification scores and outcomes analysis $[6,7]$ and the reason to strictly look after clinical data and not administrative data [8].

A safe surgeon updates knowledge, adapts new and useful technology, understands the professional guidelines and constantly seeks to improve knowledge and performance. A safe surgeon teaches students with clear scientific explanations and rationale for his actions, methods.

A safe surgeon is responsive to patient's needs, receptive to suggestions from patients, colleagues, teammates in making the patient feel important. A safe surgeon expresses gratitude to other team members openly and is appreciative of any special effort by anyone.

A safe surgeon is calm, collected and demonstrates equanimity, ability and leadership in any crisis. As stated earlier, the attributes of the surgeon are maturity of judgement, dexterity of hand, serenity in crisis and devotion in teaching [9].
A safe surgeon pays close attention to ethical and moral issues pertaining to professional performance and accepts responsibility for all mishaps.

These are, in our experience, the essential ingredients that make cardiac surgery safe, effective, effortless and inexpensive with superior outcomes.

\section{References}

1. Bailey CP. The surgical treatment of mitral stenosis (mitral commissurotomy). Dis Chest. 1949;15:377-97.

2. Jokinen JJ, Hippelainen MJ, Turpeinen AK, Pitkanen O, Hartikainen JE. Health-related quality of life after coronary artery bypass grafting: a review of randomized controlled trials. J Card Surg. 2010;25:30917.

3. Haynes AB, Weiser TG, Berry WR, et al. A surgical safety checklist to reduce morbidity in a global population. N Engl J Med. 2009;360:491-9.

4. Senior K. WHO surgical safety checklist has value worldwide. Lancet Infect Dis. 2009;9:211.

5. Kumar TK. The second assistant in cardiac surgery: the challenges and answers. J Thorac Cardiovasc Surg. 2009;137:1311-3.

6. Torchiana DF, Meyer GS. Use of administrative data for clinical quality measurement. J Thorac Cardiovasc Surg. 2005;129:12235.

7. Nashef SA, Roques F, Michel P, Gauducheau E, Lemeshow S, Salamon R. European system for cardiac operative risk evaluation (Euro SCORE). Eur J Cardiothorac Surg. 1999;16:9-13.

8. Roques F, Nashef SA, Michel P, et al. Risk factors and outcome in European cardiac surgery: analysis of the EuroSCORE multinational database of 19030 patients. Eur J Cardiothorac Surg. 1999; 15:816-22.

9. Scannell JG. Presidential address: as I remember them. J Thorac Cardiovasc Surg. 1978;76:145-57. 